\title{
Evaluation of a Fissure Sealant Program as Part of Community-Based Teaching and Training
}

\begin{abstract}
Philippus J. van Wyk, Ph.D.; Jeroen Kroon, M.Ch.D.; John G. White, B.Ch.D., M.B.A.
Abstract: Since 1995 the Department of Community Dentistry of the University of Pretoria has been involved in the rendering of mobile primary oral health care services to children in the Hammanskraal area of Gauteng, South Africa, as part of their students' community-based training. Mokonyama Primary School was identified as the first school where a primary oral health care service could be rendered. The objective of this study was to evaluate the impact (outcomes) of a fissure sealant program on the dentition status of the school children. Seven years after the implementation of the program, the dentition status of children at Mokonyama was compared with that of a comparable group of children from the same area who were not exposed to the program. The results showed that the decayed, missing, and filled teeth in the primary dentition (dmft) in the six-year-old group in Mokonyama (1.74) did not differ significantly from the $\mathrm{dmft}$ (1.43) of the control group ( $\mathrm{p}=0.49)$. The decayed, missing, and filled teeth in the permanent dentition (DMFT) of 0.59 for the fifteen-year-old group in Mokonyama, however, differed significantly $(\mathrm{p}=0.0001)$ from the DMFT of the control group (2.38). Fifteen-year-old children in Mokonyama had 75.2 percent fewer caries than their counterparts in the control group.

Dr. van Wyk is Professor and Head, Department of Community Dentistry, University of Pretoria; Dr. Kroon is Professor and Head, Department of Community Dentistry, Medunsa; and Dr. White is Senior Stomatologist, Department of Community Dentistry, University of Pretoria. Direct correspondence and requests for reprints to Dr. P.J. van Wyk, Department of Community Dentistry, University of Pretoria, P.O. Box 1266, Pretoria, 0001, South Africa; +27-12-319-2418 phone; +27-12-323-7616 fax; pjvanwyk@medic.up.ac.za.
\end{abstract}

Key words: preventive dentistry, sealants, outcomes

Submitted for publication 9/17/03; accepted 11/14/03

$\mathrm{F}$ aculties of dentistry in South Africa are required to train their students in the principles of Primary Oral Health Care (POHC) and expose these students to community-based programs where these principles can be applied. For this purpose, the University of Pretoria acquired a facility in the Hammanskraal area, fifty kilometers north of Pretoria, where students could be exposed to these programs. Faculties of the University of Pretoria were requested to target communities in this area with their community-based programs. With this in mind and with the assistance of the community leaders, Mokonyama Primary School in the Mandelaville informal settlement was identified as the first school where a primary oral health care service could be rendered using a mobile oral health care unit. A strategy was implemented where all children at a specific school were treated first before moving on to the next school. Employing this strategy, the organizers envisaged that in the long term at least five schools from the community would be serviced by the unit rotating among these schools. The objective of this study was to evaluate the outcomes of the fissure sealant component of the oral health program on the dentition status of children at the Mokonyama Primary School seven years after implementation of the program.

\section{Materials and Methods}

The program at Mokonyama Primary School commenced in May 1995. Two dental and two oral hygiene students, supervised by a staff member of the School of Dentistry, visited the school three times a week during school terms. These final-year dental and oral hygiene students performed all examinations and treatment during their involvement in this project. Treatment need for children was documented on an examination form specially designed for this project. The children's parents were given a letter of notification that informed them of the project and the need for treatment. Parents were requested to provide consent before treatment could commence.

The program consisted of the following treatment modalities: screenings, fissure sealants, scaling and polishing, simple restorations, extractions, and bleaching of vital teeth on a limited scale (fluorosed stained teeth). The main focus of the program was on the prevention of dental caries, and as a result the placement of fissure sealants played a very important role. The rationale for the use of fissure sealants instead of other preventive modalities was based on recommendations by Bohannan et al. ${ }^{1}$ which contends that the pattern of dental caries has changed 
to one where the majority of caries presents on occlusal surfaces.

The following criteria were applied in the selection of teeth ${ }^{2}$ :

1. Occlusal morphology - teeth with deep, narrow pits and fissures were sealed.

2. Age of teeth - teeth that have erupted recently or fairly recently were sealed.

3. Teeth in mouths where occlusal as well as few interproximal lesions or restorations occurred were sealed.

Mokonyama Primary School is situated in the Hammanskraal area, in the northern part of the Gauteng Province of South Africa. Drinking water to the area (Mokonyama Primary School, Hammanskraal area, and the Moretele Health District) is provided by Magalies Water via the Temba Water Treatment Plant. According to Magalies Water, the fluoride content of the drinking water ranges between 0.32 and $0.60 \mathrm{mg} \mathrm{F} / 1$ with a mean of 0.44 $\mathrm{mg} \mathrm{F} / \mathrm{l}^{3}$. However, water samples taken at the school and tested for fluoride content never yielded more than $0.21 \mathrm{mg} \mathrm{F} / \mathrm{l}$. Many people in the area living on farms and small plots of land make use of water from boreholes and wells that contain more than the optimum level of fluoride. The fluoride content of these boreholes and wells ranges from 0 to $13.9 \mathrm{mg} \mathrm{F} / \mathrm{l}^{4}$.

During the 1999-2002 National Children's Oral Health Survey (NCOHS) ${ }^{5}$ in South Africa, four-tofive-, six-, twelve-, and fifteen-year-old children in the Moretele Health District were examined for inter alia dentition (caries) status. The sample for the North West Province was representative of the health districts for this province. The decision was made to compare the dentition status of children of the Mokonyama Primary School, who were exposed to the program, to that of children not exposed to the program, i.e., children from the Moretele Health District. This decision was made because of two factors: 1) children from the Mokonyama Primary School are drawn from a large area, including the Moretele Health District, and they receive the same drinking water as children of the Moretele Health District, and 2) there is no apparent difference in the socioeconomic status of children at the Mokonyama Primary School and the rest of the area.

To assess the dentition status of children of Mokonyama Primary School, an oral health survey using the same criteria and age groups as the 19992002 NCOHS was conducted. Sixty children in each of the age groups twelve and fifteen were selected from children in the school using a table of random numbers and examined for dentition status and dental fluorosis according to the World Health Organization's guidelines. ${ }^{6}$ All the children in the sixyear-old group in the school were also included in the sample. A single examiner who was calibrated during the National Children's Oral Health Survey $(1999-2002)^{5}$ performed the final examinations of the sample.

\section{Results and Discussion}

During the seven years of the program (19952001), 4,723 children were screened, of which 2,501 received treatment, an average of 358 children per year. Of the 11,461 dental procedures performed, 2.4 percent were extractions, 75.5 percent were preventive procedures, and 22.1 percent were restorative. Of the preventive procedures, 95.2 percent or 8,288 were fissure sealants, and the remaining 4.8 percent were scaling and polishing. An average of 3.3 fissure sealants were placed per child treated.

The dentition status of children at Mokonyama Primary School and children of the Moretele Health District is compared in Tables 1 and 2. The data presented in Table 1 shows that in the six-year-old group the prevalence of dental caries is higher in the Mokonyama group (49.2 percent) than in the Moretele group (43.3 percent). Table 1 also shows that the percentage of children with caries experience more than doubles between the ages of twelve and fifteen in Moretele, while children in Mokonyama only experienced a slight increase in caries between these ages, from 24.1 percent to 26.8 percent. This dramatic reduction in the prevalence of dental caries demonstrates the appropriateness of the criteria used to select the group of children susceptible to dental caries.

The severity of dental caries expressed as the $\mathrm{dmft} / \mathrm{DMFT}$ and its components for the two groups for the different age groups is compared in Table 2. The dmft in the six-year-old group in Mokonyama (1.74) is higher than that for Moretele (1.43). This difference was not statistically significant $(p=0.4895)$. In both these groups the decayed component (dt) constitutes more than 90 percent of the total dmft.

The results for the twelve-year-old group (Table 2) showed that children in Mokonyama who were exposed to the program had a much lower DMFT (0.42) than the Moretele group (1.07). The difference between these two groups was statistically sig- 
Table 1. Prevalence of dental caries in Mokonyama and Moretele in the six-, twelve-, and fifteen-year-old groups

\begin{tabular}{|c|c|c|c|c|}
\hline Age Group & & konyama (Experimental) & & Moretele (Control) \\
\hline & $\mathrm{n}$ & Percentage Prevalence & $\mathrm{n}$ & Percentage Prevalence \\
\hline 6 year & 59 & 49.2 & 60 & 43.3 \\
\hline 12 year & 79 & 24.1 & 60 & 31.9 \\
\hline 15 year & 67 & 26.8 & 60 & 63.2 \\
\hline
\end{tabular}

Table 2. Severity of dental caries in Mokonyama and Moretele

\begin{tabular}{|c|c|c|c|c|}
\hline Age Group & Component & $\begin{array}{c}\text { Mokonyama (Experimental) } \\
\text { Mean (sd) }\end{array}$ & $\begin{array}{l}\text { Moretele (Control) } \\
\text { Mean (sd) }\end{array}$ & \\
\hline 6 year & $\begin{array}{l}\mathrm{dt} \\
\mathrm{mt} \\
\mathrm{ft} \\
\mathrm{dmft}\end{array}$ & $\begin{array}{l}1.67(2.42) \\
0.02(0.12) \\
0.05(0.28) \\
1.74(2.58)\end{array}$ & $\begin{array}{l}1.30(2.14) \\
0.13(0.26) \\
0 \\
1.43(2.35)\end{array}$ & $p>0.05$ \\
\hline 12 year & $\begin{array}{l}\text { DT } \\
\text { MT } \\
\text { FT } \\
\text { DMFT }\end{array}$ & $\begin{array}{l}0.28(0.58) \\
0.04(0.25) \\
0.1(0.41) \\
0.42(0.76)\end{array}$ & $\begin{array}{l}1.05(2.34) \\
0.02(0.13) \\
0 \\
1.07(2.34)\end{array}$ & $p<0.05$ \\
\hline 15 year & $\begin{array}{l}\text { DT } \\
\text { MT } \\
\text { FT } \\
\text { DMFT }\end{array}$ & $\begin{array}{l}0.22(0.67) \\
0.06(0.24) \\
0.31(0.84) \\
0.59(1.168)\end{array}$ & $\begin{array}{l}2.33(2.67) \\
0 \\
0.05(0.39) \\
2.38(2.68)\end{array}$ & $p<0.05$ \\
\hline
\end{tabular}

nificant $(\mathrm{p}=0.0384)$. As expected, the decayed component $(\mathrm{dt})$ of 0.28 in the case of Mokonyama constituted a lower percentage (66.7 percent) of the total DMFT than the decayed component of 1.05 for the Moretele group (98.1 percent). Although the decayed component was lower in Mokonyama than in Moretele, it could still be regarded as high, especially if the availability of a regular dental service on the school premises is taken into account. The high level of untreated caries within the school in the twelveyear-old group could be attributed to the following factors:

- The service is voluntary. Whether a child is included in the program or not depends to a large extent on the consent of the parents and the subsequent return of the consent form to the school.

- Instability of the population. Because of the high level of unemployment levels in the area, there is a migration of people in and out of the area.

- Absenteeism. Children are screened in groups (classes), and if a child is not present on the day of the screening, he or she is not included in the treatment program.

Because the objective of this study was to evaluate the outcomes of this community-based program, the assessment will therefore focus on the fif- teen-year-old group. The DMFT for this group in Mokonyama was 0.59 , while the DMFT for the Moretele group was 2.38. The difference between the two groups was statistically significant $(p=0.0001)$. The results of this study showed that fifteen-year-old children in Mokonyama had 75.2 percent fewer caries than their counterparts in Moretele. This figure compares favorably with a 45 percent reduction in caries compared to DMFT scores at the start of a program over a two-year period in Guam in a fluoride deficient area. ${ }^{7}$ Mertz-Fairhurst et al. ${ }^{8}$ reported a reduction of more than 50 percent in caries after a seven-year period following a single application of fissure sealants. In the case of Mokonyama, the majority of children were screened and treated twice over the seven-year period.

The high levels of caries reduction achieved in the Mokonyama group could be attributed to the repeated application of fissure sealants and the fact that a large percentage of the children were exposed to high levels of fluoride. The prevalence of moderate and severe dental fluorosis ranged from 28.1 percent in Mokonyama to 38.3 percent for the Moretele Health District in the twelve-year-old group. BackerDirks et al. ${ }^{9}$ found that approximately 75 percent of protection from water fluoridation was confined to 
Table 3. DMFT per tooth group and the percentage contribution of each tooth group to the total DMFT in the fifteen-year-old group

\begin{tabular}{|c|c|c|c|}
\hline Tooth Group & Mokonyama (Experimental) & More & ele (Control) \\
\hline First permanent molars & $0.27 \quad$ (45 percent) & 1.00 & (42 percent) \\
\hline Second permanent molars & (47 percent) & 1.22 & (51 percent) \\
\hline Premolars & (8 percent) & 0.11 & (5 percent) \\
\hline Other & 0 & 0.05 & (2 percent) \\
\hline Total DMFT & 0.59 & 2.38 & \\
\hline$p>0.05$ & & & \\
\hline
\end{tabular}

smooth surfaces and only 25-30 percent protection was obtained in pits and fissures. In the fifteen-yearold group, the decayed component or untreated caries constituted 37.3 percent in the Mokonyama group and 97.4 percent in the Moretele group.

To evaluate the impact of the program on the different teeth in the mouth, the teeth of the fifteenyear-old group were divided into premolars, first permanent molars, second permanent molars, and other teeth. For each of these groups of teeth, a DMFT and the percentage contribution of each tooth group to the total caries profile (DMFT) were calculated.

From Table 3 it is clear that caries on the first and second permanent molars were responsible for more than 90 percent of the total caries profile in both these groups. Caries on premolars constituted only a small percentage of the total DMFT. Therefore, inclusion of premolars in the preventive program, especially where there are low caries prevalence levels, should be questioned. The data in Table 3 were further analyzed using Chi-square analysis to determine whether a particular tooth group was responsible for the lower DMFT. The results of the analysis showed that the proportions of the two groups did not differ significantly ( $p>0.05)$, implying that no particular tooth group was responsible for the lower DMFT level in the Mokonyama group and that the program impacted equally on the three groups of teeth. This conclusion, however, is only valid if the program focuses on all age groups. In cases where particular age groups or tooth groups are targeted, the results will obviously be different.

The data for the fifteen-year-old group in Moretele was further analyzed to examine the distribution of dental caries in the mandible and the maxilla for the different tooth groups (Table 4). In Moretele, almost 60 percent of the caries occurred in the mandible, with almost 30 percent of all caries presenting in the mandibular second permanent molar followed by the mandibular first molar (24.5 per- cent). No caries occurred on the mandibular anterior teeth while very little caries ( 0.7 percent) was detected on the maxillary premolars. These data showed that the mandibular permanent molars, followed by the maxillary permanent molars, were the most vulnerable teeth in the mouth. Only 4.7 percent of caries occurred on the premolars. According to Eklund and Ismail, ${ }^{10}$ and based on the prevalence of proximal and occlusal caries over a period of thirty-five years (i.e., where the occlusal surfaces are carious but the proximals are not), different caries patterns presented for molars compared to that for premolars. In molars 50 percent of teeth presented with occlusal caries or restorations that could have been potentially avoided. On the other hand, less than 10 percent of premolars presented with caries or restorations on the occlusal surfaces. As a result, sealants could have saved the need for occlusal restorations in only 10 percent of premolars.

\section{Recommendations}

It is conceded that some degree of overtreatment with regard to fissure sealants occurred during the program at Hammanskraal. In view of the

Table 4. Percentage distribution of dental caries in the mandible and the maxilla in the fifteen-year-old group in Moretele per tooth group

\begin{tabular}{lcc} 
Tooth Group & Maxilla & Mandible \\
\hline Anterior teeth (3-3) & 2.2 & 0 \\
Premolars & 0.7 & 4.0 \\
First permanent molars & 17.0 & 24.5 \\
Second permanent molars & 21.7 & 29.9 \\
Total & 41.6 & 58.4
\end{tabular}




\section{Table 5. Diagnostic criteria for pit and fissure caries}

Clinical sign

- Explorer catch

- Discoloration

- Enamel softness

Diagnosis

Treatment options

$\begin{array}{cc}\text { No } & \text { Yes } \\ \text { No } & \text { No } \\ \text { No } & \text { No } \\ \text { Sound } & \text { Sound } \\ \text { No sealant } & \text { Sealant }\end{array}$

$\begin{array}{cc}\text { Yes } & \text { Yes } \\ \text { Yes } & \text { Yes } \\ \text { No } & \text { Yes } \\ \text { Questionable } & \text { Carious }\end{array}$

Sealant
Preventive/Resin

Conventional restoration

Source: Ripa LW, Wolf MS. Preventive resin restorations; indications, technique and success. Quintessence Int 1992;23: 307-15.

experience gained with the Hammanskraal program and guidelines provided by Burt ${ }^{11}$ and Ripa and Wolf, ${ }^{12}$ the following recommendations are made regarding the selection of children and teeth for fissure sealant programs:

1. Sealants should be applied only to the occlusal fissures of permanent molars within four years of eruption. If a second molar is the prime tooth to be sealed, a non-restored first molar can also be sealed at the same time.

2. Based on the findings of this study and the previous study by Eklund and Ismail, ${ }^{10}$ no sealants should be placed on premolars.

3. Teeth eligible for sealing must have caries-free approximal surfaces.

4. A major reason for overtreatment is that the diagnosis of deep, narrow pits and fissures is very subjective and depends to a large extent on the interpretation of the operator/examiner. The application of the criteria for the diagnosis of pit and fissure caries described in Table 5 and proposed by Ripa and Wolf ${ }^{12}$ will help to eliminate this problem. They proposed a visual-tactile examination of the tooth surface using a mirror and an explorer and only if the explorer catches should the tooth be sealed. A tooth should also be sealed if the explorer catches and there is discoloration of the fissures.

\section{Conclusions}

Since the completion of the program at Mokonyama, the revised criteria have been included in the curricula of dental and oral hygiene students at the School of Dentistry of the University of Pretoria. Based on the seven-year experience in Hammanskraal, pit and fissure sealants have been shown to be an effective adjunct to other caries preventive procedures and should be included in the preventive armamentarium of both public oral health programs and private practitioners.

\section{REFERENCES}

1. Bohannan HM, Disney JA, Groves RC, Bader JD, Stephen PK, Bell RM. Indications for sealant use in a community-based preventive dentistry program. J Dent Educ 1984;48(2 Suppl):145-55.

2. British Paedodontic Society. A policy document for fissure sealants. Br Dent J 1987;163(2):42-3.

3. Magalies W. Letter to PJ van Wyk. Evaluation of provisional application to be exempted from fluoridation, February 1999 .

4. Mothusi B. Letter to the Department of Health. Fluoride levels of drinking water in the North West Province, May 1999.

5. Department of Health. Report: national children's oral health survey South Africa. PJ van Wyk, ed. Pretoria: Department of Health, 2003:2-6.

6. Oral health surveys: basic methods. $3^{\text {rd }}$ ed. Geneva: World Health Organization, 1997.

7. Sterrit GR, Frew RA. Evaluation of a clinic-based sealant program. J Public Health Dent 1988;48(4):220-4.

8. Mertz-Fairhurst EJ, Fairhurst W, Williams JE, Della Custiana VE, Brooks JD. A comparative clinical study of two pit and fissure sealants: 7 year results in Augusta, GA. J Am Dent Assoc 1984;109:252-5.

9. Backer-Dirks O, Houwink B, Kwant GW. The result of six and a half years of artificial fluoridation of drinking water in the Netherlands. Arch Oral Biol 1961;5:284-300.

10. Eklund SA, Ismail AI. Time of development of occlusal and proximal lesions: implications for fissure sealants. J Public Health Dent 1986;46(2):114-21.

11. Burt BA. Cost-effectiveness of sealants in the private practice and standards for use in prepaid dental care (information report prepared for the ADA Council of Dental Research). J Am Dent Assoc 1985;110:103-7.

12. Ripa LW, Wolf MS. Preventive resin restorations; indications, technique and success. Quintessence Int 1992;23:307-15. 